DOI 10.37882/2500-3682.2021.02.25

\title{
ВЗАИМОСВЯЗЬ САМОРЕГУЛЯЦИИ И СОЦИАЛЬНОЙ АДАПТАЦИИ ПОДРОСТКОВ С ИНТЕЛЛЕКТУАЛЬНЫМИ НАРУШЕНИЯМИ
}

\section{INTERRELATION BETWEEN SELF- REGULATION AND SOCIAL ADAPTATION OF ADOLESCENTS WITH INTELLECTUAL DISORDERS}

\section{Samoylyuk \\ K. Logunova \\ O. Khripko}

Summary: The issue of self-regulation in adolescents with intellectual disorders (intellectual disability) is one of the least researched areas in special psychology. The article looks into correlation between selfregulation and social adaptation of adolescents with intellectual disorders. The following methods and techniques were used: psychodiagnostic method (based on A.K. Osnitsky's method of "SelfRegulation" (modification)); expert assessment (teacher's questionnaire aimed to determine how well constituents of cognitive development are formed (regulatory constituent) (by S.A. Domishkevich) and assessment scale of social adaptation (by E.L. Indenbaum); statistics method. Self-regulation is characterized in accordance with different levels of adaptation of intellectually impaired schoolchildren. It has been proven that those test subjects with higher levels of self-regulation go through social adaptation more smoothly.

Keywords: adolescents with intellectual disorders (intellectual disability), self-regulation in adolescents with intellectual disorders, social adaptation of schoolchildren with mental disability, self-regulation as a factor of social adaptation.

\section{Введение}

$\Pi$ о мнению многих исследователей, достаточная саморегуляция обуславливает успешность любой деятельности человека $[3,6,10]$. Подростковый возраст является благополучным для развития саморегуляции, но даже дети с нормотипичным развитием сталкиваются с рядом проблем в силу возрастных ососбенностей [17].

При умственной отсталости нарушения саморегуляции у подростков являются закономерными $[8,14]$. Ее недостатки проявляются в трудностях прогнозирования, планирования и оценке деятельности; импульсивностью, неорганизованностью, низким самоконтролем в учебной ситуации, в межличностном общении, при выполнении трудовых действий и др. $[8,9,14,18]$. Классик

\author{
Самойлюк Людмила Александровна \\ К.nсх.н., доцент, Иркутский государственный \\ университет \\ lyuda1221@rambler.ru
}

Логунова Кристина Геннадьевна

Старший преподаватель, Иркутский государственный университет

kristiana-irk@yandex.ru

Хрипко Ольга Сергеевна

Педагог-психолог, Марковская средняя общеобразовательная школа (Иркутский район) xripko_olga@mail.ru

Аннотация: Проблема саморегуляции у подростов с интеллектуальными нарушениями (умственной отсталостью) является одной из малоизученных в специальной психологии. В статье рассматриваются результаты исследования взаимосвязи саморегуляции и социальной адаптации у подростков с интеллектуальными нарушениями. Для исследования использованы методы и методики: психодиагностический (методика А.К. Осницкого «Саморегуляция» (модификация); экспертной оценки (учительский опросник сформированности компонентов учебно-познавательной деятельности (регулятивный компонент) (С.А. Домишкевич) и шкала оценки социальной адаптации (Е.Л. Инденбаум); статистический. Представлена характеристика саморегуляции при разных уровнях адаптации умственно отсталых школьников. Показано, что при более высоком уровне саморегуляции, испытуемые демонстрируют лучшую социальную адаптацию.

Ключевые слова: подростки с интеллектуальными нарушениями (умственной отсталостью), саморегуляция подростков с интеллектуальными нарушениями, социальная адаптация школьников с умственной отсталостью, саморегуляция как фактор социальной адаптации.

отечественной дефектологии С.Я. Рубинштейн отмечала, что в наибольшей степени у умственно отсталых детей страдает способность к произвольному побуждению или торможению действий, т.е. то, что в литературе называют саморегуляцией. Слабое развитие навыков самоконтроля и саморегуляции значительно затрудняют социально-трудовую адаптацию школьников с нарушением интеллекта [16].

В свою очередь, умение контролировать свои эмоции, способность к целеполаганию, целенаправленная активность, ее устойчивость, выносливость, приспособление к требованиям окружающей среды являются критериями прогноза социальной адаптации $[7,11]$.

При интеллектуальных нарушениях наблюдаются сложности социальной адаптации подростков, которые 
вызваны наличием детерминированных дефектом трудностей осмысления окружающей реальности. Дефицит социальных и познавательных способностей обуславливает трудности социальной нормативности поведения в самых разнообразных ситуациях межличностного общения, частые конфликты со взрослыми и сверстниками, неполноценные представления об окружающей среде и другие негативные проявления [4, 5, 7, 12].

Многие исследователи отмечают, что одним из необходимых условий социальной адаптации является хорошая саморегуляция $[1,2,13]$.

Целью нашего исследования явилось изучение взаимосвязи саморегуляции и социальной адаптации подростков с легкой умственной отсталостью.

\section{Материалы и методы исследования}

Для изучения саморегуляции подростков с интеллектуальными нарушениями была использована методика А.К. Осницкого «Саморегуляция» (в нашей модификации). Опросник состоял из 10 суждений и оценивались следующие характеристики: целеполагание, программирование действий, оценивание результатов, обеспеченность регуляции в целом, коррекция результатов и способов действий, упорядоченность деятельности, детализация регуляции действий, осознанность (осознаваемая контролируемость) действий, ответственность в делах и поступках, вовлечение полезных привычек.

С целью верификации полученных данных самооценки саморегуляции подростками использовался блок вопросов «Регулятивный компонент» опросника сформированности компонентов учебно-познавательной деятельности (С.А. Домишкевич) для педагогов. Экспертная оценка регулятивного компонента проходила по следующим критериям: умение формулировать цель; сопоставлять полученные результаты с требуемым; способность заметить ошибку при выполнении задания и исправить ее самостоятельно; умение действовать без известного заранее алгоритма. С помощью шкалы оценки социальной адаптации (Е.Л. Инденбаум) изучались уровень бытовых навыков, социально-бытовая ориентировка, взаимодействие со сверстниками, взаимодействие со взрослыми, умение вести себя в здании школы и на групповых мероприятиях, усвоение учебного материала, отношение к учебе, трудовые умения и навыки, отношение к труду, социальная приспособленность.

Для статистической обработки результатов использовалась программа STATISTICA 6.1 (ряды распределения, средние значения, коэффициент корреляции Спирмена, оценка достоверности различий $\mathrm{t}-$ критерий Стьюдента).

\section{Результаты исследования}

Анализ результатов исследования показал, что все подростки с интеллектуальными нарушениями испытывали трудности в социальной адаптации. Это согласуется с литературными данными в ряде исследований. Общее психическое недоразвитие обуславливает ограничения социальной адаптации, продолжающиеся на всем периоде онтогенеза $[4,7]$. Исследуемая выборка поделилась на две, практически равные по количеству, группы - «частично адаптированные» (48 \%) и «дезадаптированные» (52 \%). Частично адаптированные школьники обнаруживали более высокие показатели по всем шкалам. Педагоги отмечали у испытуемых в этой группе хорошие навыки ориентировки в бытовых вопросах, относительно успешное взаимодействие со взрослыми (педагогами) и сверстниками, демонстрирующее усвоенные правила социализированного поведения.

Для дезадаптированных подростков с умственной отсталостью были характерны низкий уровень сформированности социально-бытовой ориентировки, проявляющихся в трудностях самостоятельного соблюдения гигиены, порядка, пользования бытовыми приборами. Наблюдались трудности понимания смысла различных коммуникативных ситуаций, позиционирования себя в общении со взрослыми и сверстниками, самостоятельного соблюдения социальных норм. Эти испытуемые с трудом овладевали трудовыми умениями и навыками.

Результаты изучения саморегуляции подростков с интеллектуальными нарушениями показали, что большинство из них обнаруживают средний уровень саморегуляции (62 \%), два школьника оказалось на достаточном и $24 \%$ - на низком. Высокого уровня саморегуляции у подростков с интеллектуальными нарушениями обнаружено не было.

Мы предполагали, что существует взаимосвязь между саморегуляцией и социальной адаптацией подростков с интеллектуальными нарушениями. Результаты исследования подтвердили нашу гипотезу. Оказалось, что у подростков с лучшей саморегуляцией обнаруживалась более высокая социальная адаптация. На рисунке 1 представлен сопоставительный профиль показателей социальной адаптации умственно отсталых подростков с разными уровнями саморегуляции.

Как видно из рис.1., при достаточном уровне саморегуляции практически все показатели шкалы социальной адаптации выше, чем при среднем и низком. Согласно полученным данным, у умственно отсталых подростков с достаточным уровнем саморегуляции были достоверно лучше сформированы, чем у испытуемых с низким:

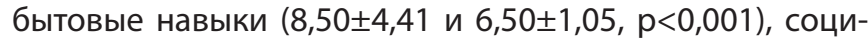

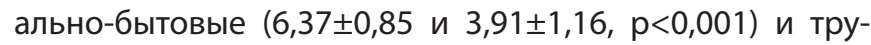




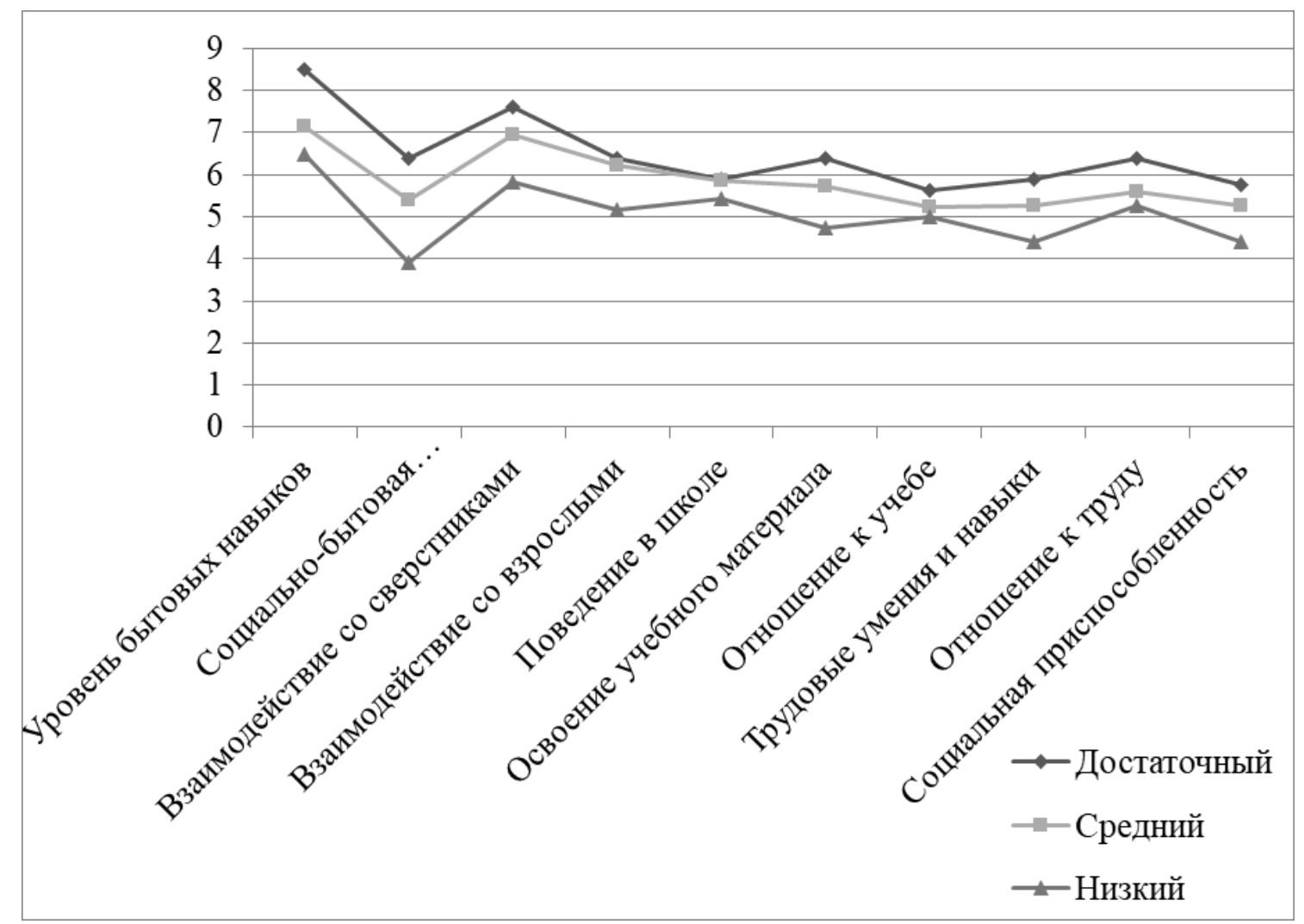

Рис. 1. Сопоставительный профиль показателей социальной адаптации подростков с интеллектуальными нарушениями с разными уровнями саморегуляции $(\mathrm{Mx} \pm \sigma)$

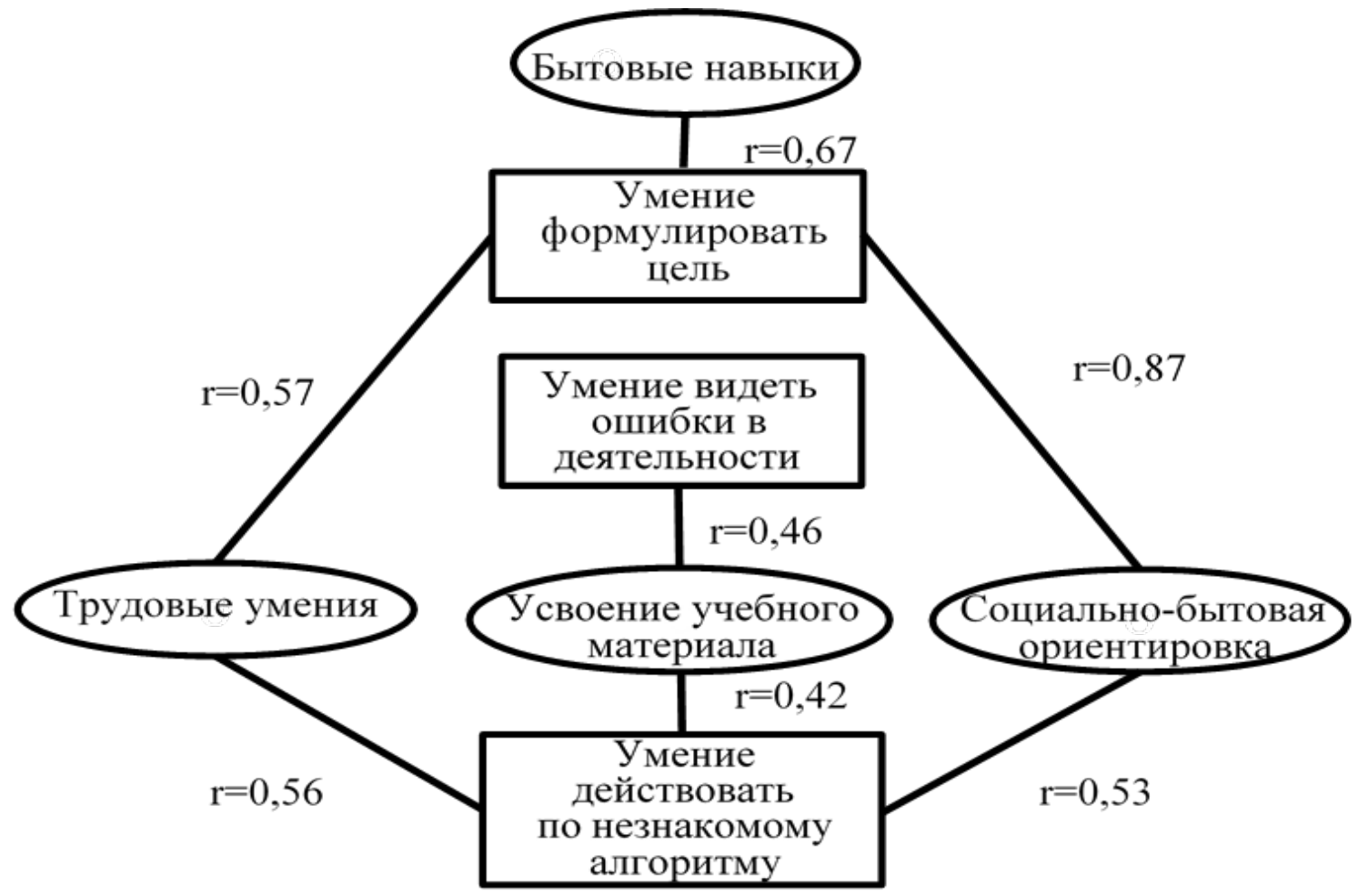

Рис. 2. Взаимосвязь параметров саморегуляции и социальной адаптации у подростков с интеллектуальными нарушениями, при $\mathrm{p}<0,05$ 
довые $(5,87 \pm 0,75$ и 4,42 $\pm 0,97, p<0,03)$. Кроме того, было выявлено, что эти школьники характеризовались более позитивным отношением к труду $(6,37 \pm 0,25$ и 5,25 $\pm 1,17$, $\mathrm{p}<0,03)$, умением выстраивать взаимодействие со сверстниками $(7,62 \pm 0,85$ и 5,83 $\pm 1,33, p<0,04)$ и демонстриро-

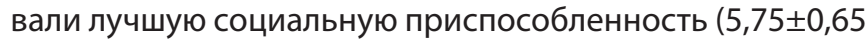
и 4,42 $\pm 0,74, p<0,01)$. Все эти характеристики, согласно ФГОС О УО (ИН), относятся к сфере жизненной компетенции, формирование которой является одной из приоритетных задач образования детей и подростков с интеллектуальными нарушениями.

Наряду с выявленными характеристиками социальной адаптации, у всех испытуемых педагоги отмечали недостаточность мотивации. Подростки проявляли относительно равнодушное отношение к учебе, как необходимости, которой нельзя избежать. Это согласуется с результатами, полученными в других исследованиях, где было показано, что становление положительной мотивации учебной деятельности школьников с умственной отсталостью затруднено и обусловлено рядом факторов, среди которых обедненность внутреннего мира, слабый интерес школьников к содержанию учения, низкие возможности в преодолении учебных трудностей [15]. Кроме того, наблюдались недостатки регулирования своего поведения в школе, зависящего от степени «интересности», настроения школьников и характеризующегося не- стабильностью, отклонениями от социально-нормативного поведения.

Корреляционный анализ показал ряд достоверно значимых взаимосвязей саморегуляции и социальной адаптации. На рисунке 2 отражена взаимосвязь параметров саморегуляции и социальной адаптации у подростков с интеллектуальными нарушениями. Так, оказалось, что целеполагание взаимосвязано со сформированностью трудовых и бытовых навыков. Чем выше показатели умения ставить цели, тем лучше сформированы бытовые, и, что очень важно для послешкольной социализации, трудовые навыки. Кроме того, умение действовать по незнакомому алгоритму и видеть ошибки позитивно влияет на усвоение академических знаний. На наш взгляд, полученные сведения необходимо учитывать при планировании коррекционной работы с рассматриваемой категорией подростков.

Основываясь на полученных сведениях, мы полагаем, что хорошую саморегуляцию можно считать прогностически благоприятным признаком для социальной адаптации подростков с интеллектуальными нарушениями. Результаты исследования могут представлять интерес для педагогов, работающих в коррекционных и инклюзивных образовательных организациях со школьниками с интеллектуальными нарушениями.

\section{ЛИТЕРАТУРА}

1. Астахова, Н.В. Психологические особенности саморегуляции учебной деятельности у подростков в условиях коррекционно-развивающего обучения: дис. ... канд. психол. наук / Астахова Наталья Владимировна. - М., 2007. - 206 с.

2. Бабкина, Н.В. Психолого-педагогические условия формирования саморегуляции познавательной деятельности у младших школьников с задержкой психического развития: дис. ... канд. психол. наук / Бабкина Наталия Викторовна. - М., 2003. - 170 с.

3. Зобков, А.В. Психолого-акмеологичекая концепция интегративно-динамической саморегуляции субъектами учебной деятельности : автореф. дис. .... д. пс. наук / А.В. Зобков. - Кострома, 2014. - с. 52.

4. Инденбаум, Е.Л. Психосоциальное развитие подростков с легкими формами интеллектуальной недостаточности: дис. .... док-ра психол. наук / Инденбаум Елена Леонидовна. - М., 2011. - 353 с.

5. Колосова, Т.А. Особенности социально-психологической адаптации умственно отсталых подростков / Т.А. Колосова, А.С. Григорьева // Успехи современной науки. - 2016. - № 3. - С. 130 - 132.

6. Конопкин, 0.А. Психологические механизмы регуляции деятельности / 0.А. Конопкин. - М.: Ленанд, 2011. - 320 с.

7. Коробейников, И.А. Нарушения развития и социальная адаптация / И.А. Коробейников. - М.: ПЕР (Э, 2002. - 192 с.

8. Лубовский, В.И. Развитие словесной регуляции действий у детей (при нормальном и нарушенном развитии) / В.И. Лубовский. - М.: Буки Веди, 2013. $198 \mathrm{c}$.

9. Метиева, Л.А. Формирование саморегуляции в процессе учебной деятельности у младших школьников с интеллектуальной недостаточностью: дис. ... канд. психол. наук / Метиева Людмила Анатольевна. - Н. Новгород, 2003. - 249 с.

10. Моросанова, В.И. Самосознание и саморегуляция поведения / В.И. Моросанова, Е.А. Аронова. - М.: Ин-т психологии РАН, 2007. - 214 с.

11. Налчаджян, А.А. Социально-психическая адаптация личности: формы, механизмы и стратегии [Электронный ресурс] / А. А. Налчаджян. - Ереван: Издво АН-Армян. ССР, 1988. - 263 с. - Режим доступа: URL: https://gigabaza.ru/doc/76246.html (дата обращения: 15.10.2020).

12. Омарова, П.О. Социальная адаптация детей с нарушениями интеллекта в полиэтнической среде [Электронный ресурс] / П.0. Омарова // Научный электронный архив. - 2010. - 14.29.21. - С. 5 - 9. - Режим доступа: URL: http://econf.rae.ru/article/5710 (дата обращения: 13.10.2020).

13. Осницкий, А.К. Психологические механизмы самостоятельности / А.К. Осницкий. - М.-Обнинск: ИГ-СОЦИН, 2010. - 232 с.

14. Петрова, В.Г. Психология умственно отсталых школьников / В.Г. Петрова, И.В. Белякова. - М.: Академия, 2002. - 160 с.

15. Толстикова, 0.Н. Факторы формирования мотивации учебной деятельности умственно отсталых младших школьников : автореф. дис. ... канд. пс. наук 
/ 0.Н. Толстикова. - СПб, 2013. - с. 25.

16. Цуциева, Ж.Ч. Психологические особенности социальнотрудовой адаптации умственно отсталых подростков: дис. ... канд. псих. наук / Цуциева Жанна Черменовна. - СПб., 2003. - 136 с.

17. Черкевич, Е.А. Формирование саморегуляции психических состояний подростков: автореф. дис. ... канд. пс. наук / Е.А. Черкевич. - 0мск, 2007. - с. 23.

18. Шиф, Ж.И. Психологическое изучение основных вопросов обучения аномальных детей [Электронный ресурс] / Ж.И. Шиф // Альманах института коррекционной педагогоки. - 2015. - №22. - С. 42 - 49. - Режим доступа: URL: https://alldef.ru/ru/articles/almanah-22/psixologicheskoe-izuchenie-osnovnyixvoprosov-obucheniya-anomalnyix-detej (дата обращения: 15.09.2020).$$
\text { ๑ Самойлюк Людмила Александровна (lyuda1221@rambler.ru), Логунова Кристина Геннадьевна (kristiana-irk@yandex.ru), }
$$$$
\text { Хрипко Ольга Сергеевна (xripko_olga@mail.ru). }
$$$$
\text { Журнал «Современная наука: актуальные проблемы теории и практики» }
$$

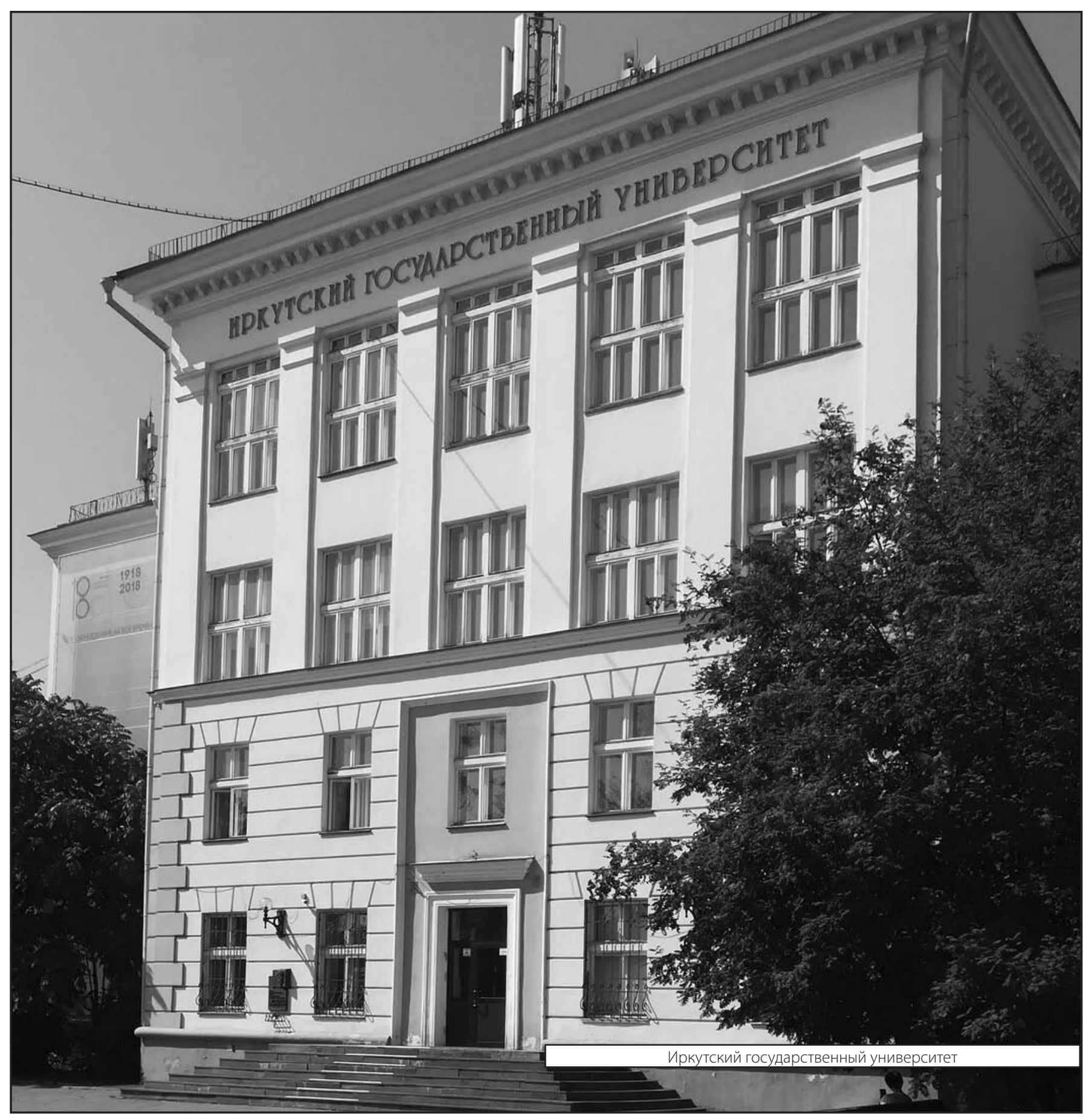

